\title{
Laticauda frontalis (de Vis, 1905) and Laticauda saintgironsi n.sp. from Vanuatu and New Caledonia (Serpentes: Elapidae: Laticaudinae)- a New Lineage of Sea Kraits?
}

\author{
HAROLD G. COGGER ${ }^{1 *}$ AND HAROLD F. HEATWOLE ${ }^{2}$ \\ ${ }^{1}$ John Evans Memorial Fellow, Australian Museum, 6 College Street, Sydney NSW 2010, Australia \\ h.cogger@bigpond.com \\ ${ }^{2}$ Department of Zoology, North Carolina State University, Raleigh, NC27695-7617, USA and \\ School of Environmental Tropical Studies and Geography, \\ James Cook University, Townsville Queensland 4811, Australia \\ harold_heatwole@ncsu.edu
}

\begin{abstract}
The sea krait Laticauda colubrina is the most widespread member of its genus, extending from the Bay of Bengal through much of Asia and the Indo-Malayan Archipelago to New Guinea and many islands of the western Pacific Ocean. Unconfirmed records of the species may extend the range to the western coast of Central America. The species is subject to marked geographic variation in a number of morphological and meristic characters that have to date defied finer taxonomic resolution.

Two members of this complex previously subsumed under the specific name colubrina are here formally elevated to full species status. One species-Laticauda saintgironsi $n$.sp.-Consists of those populations of $L$. colubrina s.l. found around the coast and in the coastal waters of the main island of New Caledonia. The second species_Laticauda frontalis (de Vis, 1905) - is a dwarf species found in sympatry and syntopy with Laticauda colubrina in Vanuatu and the Loyalty Islands of New Caledonia.
\end{abstract}

Cogger, Harold G., \& Harold F. Heatwole, 2006. Laticauda frontalis (de Vis, 1905) and Laticauda saintgironsi n.sp. from Vanuatu and New Caledonia (Serpentes: Elapidae: Laticaudinae)—a new lineage of sea kraits? Records of the Australian Museum 58(2): 245-256.

Sea kraits are typically distinctively banded marine snakes that occur from the tropical western Pacific Ocean through the Papuan and Indo-Malaysian regions to the Philippines, the Ryukyu Archipelago and tropical southeast Asia to the Bay of Bengal (Smith, 1926), while McCarthy (1986) cites the following sources for records of one species (Laticauda colubrina) from the Pacific coasts of several Central American countries: Nicaragua (Villa, 1962), Mexico (Alvarez de Toro, 1982) and El Salvador (in a pers. comm. from J. Villa).
The phylogenetic and taxonomic status of this group of snakes has varied widely in the literature, but in the most recent phylogeny Scanlon \& Lee (2004) place all proteroglyphous snakes within the family Elapidae and suggest that the Laticauda group is either a basal clade within an elapid subfamily (the Hydrophiinae) or a sister clade to the Hydrophiinae (and by inference a separate subfamily, the Laticaudinae). Earlier studies (e.g., McDowell, 1985, 1987; Cadle \& Gorman, 1981; Greer, 
1998) present evidence for variations in this phylogenetic interpretation, and so we have somewhat arbitrarily treated this clade as a distinct subfamily, the Laticaudinae.

Until the present time, this family-level taxon was regarded as comprising three widely distributed species-Laticauda colubrina (Schneider, 1799), L. laticaudata (Linnaeus, 1758) and $L$. semifasciata (Reinwardt, 1837)and two geographically restricted South Pacific species (the dwarf Laticauda schistorhyncha (Günther, 1874) endemic to Niue Island and the dwarf Laticauda crockeri Slevin, 1934 confined to Lake Tenggano on Rennell Island in the Solomon Islands). A further species (Laticauda guineai) was recently described from southern New Guinea (Heatwole et al., 2005).

Since its establishment $L$. schistorhyncha has been treated as either a distinct species or as an isolated outlying Pacific subspecies of the predominantly Asian Laticauda semifasciata. As has been pointed out by McCarthy (1986) these two taxa are virtually identical in all morphological features other than size, so that some workers have regarded them as conspecific. However subsequent studies (in prep.) have shown that $L$. schistorhyncha is a distinctive dwarf species that appears to breed only on the small, isolated mid-oceanic island of Niue. We here regard it as a distinct species constituting, with $L$. semifasciata, a separate and distinctive lineage within the genus Laticauda, to which Kharin (1984) has assigned the subgeneric name Pseudolaticauda.

Historic records (Smith, 1926; McCarthy, 1986) and cited widespread distributions of this (Golay et al., 1993) and other laticaudine species from elsewhere in the Pacific, including high latitude sites in New Zealand (McCann, 1966), Tasmania (Lord, 1919) and the coast of mainland eastern Australia (Smith, 1926; McCarthy, 1986; Cogger, 1975) almost certainly represent waif individuals carried by storms and/or currents away from their normal (i.e. preferred) ranges. In most cases individuals are permanently removed, geographically and reproductively, from other members of their species and so are lost to the gene pool. Extensive surveys of the Pacific Islands over the past 40 years have failed to reveal any reproducing populations of Laticauda schistorhyncha beyond the coastal waters of Niue. Only a handful of records of other laticaudine species are known from eastern Australia over the past two centuries, and no resident populations are known from Australian tropical or temperate continental waters, despite the presence of substantial communities of Laticauda guineai in nearby coastal areas of the continuous continental shelf shared with southern Papua New Guinea.

While the data are fragmentary, all Pacific studies of Laticauda colubrina s.l. to date, based on morphological variation (McCarthy, 1986; Heatwole et al., 2005), mark/ recapture data (Guinea, 1986; Shetty, 2000), toxin chemistry and structure (Tamiya, 1985) and genetic analysis (Slowinski \& Keogh, 2000) indicate that laticaudines, both individuals and local populations, display extremely high site fidelity to particular island reef systems, with little gene flow across open seas even when such systems are geographically proximate. one of the world's most widely distributed snakes. Resident, reproducing populations range from the Bay of Bengal through the warmer parts of east and southeast Asia to the islands of the western Pacific Ocean (Smith, 1926). It is subject to considerable geographic variation in external morphological features (McCarthy, 1986), with clear mean regional differences in some external characters.

Enderman (1970) recognized six distinctive populations which he regarded as warranting subspecific recognition, including one from New Caledonia (here described as a new species, saintgironsi, below), one from Vanuatu (here shown to represent two distinct species, frontalis and colubrina), and one from Fiji (here also assigned to colubrina). Published studies of venom chemistry (Tamiya et al., 1983), karyology (Gorman, 1981), and molecular data (Cadle \& Gorman, 1981; Keogh et al., 1998; Slowinski \& Keogh, 2000) did not identify any significant species-level variation within the colubrina complex.

A cladistic analysis by McCarthy (1986), that included the five species of Laticauda then recognized as valid, produced conflicting associations of the monotypic $L$. colubrina clade with either the L. laticaudata clade (with two included species) or with the L. semifasciata clade (also with two included species). However in his phenetic analysis of 65 character states, colubrina is clearly associated with the laticaudata lineage. McCarthy concluded that while there are three distinct lineages, $L$. colubrina “... appears to be, in some ways, transitional between the L. laticaudata lineage and the divergent $L$. semifasciata lineage ... ".

The purpose of this paper is to formally redefine and diagnose Laticauda frontalis, to describe and name what we regard as its probable sister species (Laticauda saintgironsi), and so provide a diagnosis of a probably new clade within this previously monotypic lineage. A key to the species in the Laticauda colubrina complex, incorporating the two species that are the subject of this paper, is provided in Heatwole et al. (2005). 


\section{Materials and methods}

Most of the specimens listed in this paper were collected by the authors in the field and most linear measurements, weights and scale counts were made at that time on either living (including specimens released back into the wild), anaesthetized or freshly euthanased snakes. Linear measurements were made using either a steel tape or vernier calipers. Weights were taken using Pesola spring balances of a range appropriate to the size of an individual snake. Heart position was clearly visible as a strong pulse that lifted the adjacent ventral scales when a snake was laid on its back.

Statistical analyses were undertaken using the SYSTAT 10 statistical package. Differences in regression slopes between species were determined by general linear models, including the terms species, body length and the species times body length interaction. A significant interaction term was indicative of a significant difference in the regression slopes between the different species/populations. The upper limits of the graphs in Figs. 4-7 were determined by the largest specimen examined, the same scale being used on each graph to facilitate visual comparisons of the curves of individual species/populations and sexes. However the regressions of the compared curves were calculated for only that part of each graph covering the available range of values.

Further, because geographic variation in such a wideranging taxon as Laticauda colubrina s.l. is considerable (McCarthy, 1986; Heatwole et al., 2005), we have limited our definitions of both species, including the paratypic series for $L$. saintgironsi below, almost entirely to specimens that we have ourselves collected and that we can assign confidently to the relevant taxon. We have identified other specimens in museum collections around the world as belonging to these species (some only tentatively, see Heatwole et al., 2005), but we have deliberately avoided assigning type status to these other specimens.

\section{Laticauda frontalis (de Vis, 1905)}

From the time of its original description by Charles de Vis (1905) from a single juvenile, subsequent authors assigned his Platurus frontalis to the synonymy of Laticauda colubrina. The first published indication that this species represented a valid species is a statement by McCarthy (1986) that he had been advised by one of the present authors (HGC) that we had recognized from Vanuatu a "new form", smaller than and distinct from L. colubrina, to which McCarthy assigned one of his specimens. The name Laticauda frontalis was first used as the name of a valid species (but not diagnosed) by Cogger et al. (1987) in a paper devoted to a member of the laticaudata clade (Laticauda crockeri), while Greer (1998), in the absence of any published diagnosis, indicated that frontalis was valid but yet to be defined.

This species has long been confused with L. colubrina s.l. because they are both morphologically similar, geographically sympatric and ecologically syntopic. The two species occupy the same terrestrial and marine habitats, share the same prey, and even aggregate in the same shelter sites. As defined below, Laticauda frontalis is a highly distinctive dwarf species apparently confined to Vanuatu and the Loyalty Islands, despite its type locality of "New Guinea".
However, because $L$. frontalis occurs in much lower numbers than $L$. colubrina throughout the former's known range (a frontalis:colubrina ratio of 96:184 is found in our 280 Vanuatu field records), the lack of sampling at the northern end of the known geographic range of frontalis means that the northern limit of that range is unknown.

More recently the present authors, having resolved the taxonomic problems arising from the sympatry and syntopy of this cryptic species with the larger, morphologically similar colubrina, pointed out to colleagues that exploiting identical or overlapping feeding and resting habitats and food sources presented a variety of ecological and evolutionary challenges. What are the mechanisms whereby these resources are shared or partitioned, and the reproductive integrity of each species maintained,. These aspects have been the subject of several recent studies (Shine et al., 2002a,b; Reed et al., 2002).

Following is a formal redescription of:

\section{Laticauda frontalis (de Vis, 1905)}

Platurus frontalis de Vis, 1905. A new genus of lizards. Annals of the Queensland Museum, 6:48. Holotype: Queensland Museum (QM) J202 (Fig. 1). Type locality: New Guinea. Date of collection, donor and/or collector unknown.

Diagnosis. A banded sea krait of the genus Laticauda characterized by the possession of a yellow upper lip, an undivided rostral scale, an almost invariate 21 mid-body scale rows in both sexes, fewer than 209 (males) and 212 (females) ventral scales, and a maximum snout-vent length (SVL) of $654 \mathrm{~mm}$ (males) and $783 \mathrm{~mm}$ (females). It can be distinguished from L. laticaudata and $L$. crockeri by its yellow upper lip (black in laticaudata and crockeri) and from $L$. semifasciata and L. schistorhyncha by its undivided rostral. From L colubrina it may be distinguished by the following combination of characters: a lower modal midbody scale row count of 21 , lower ventral scale counts in both sexes (Table 1, Fig. 9), smaller size (Table 1) and, throughout the known area of sympatry, by the absence of a lower lateral connection between the black head band and the first black band on the neck (Fig. 2), and the failure of the dark body bands, at least anteriorly, to extend to the middle of the venter (Fig. 1).

Description of the holotype. A member of the Laticauda colubrina complex in shape; the mid-body diameter is contained 40.7 times in its snout-vent length and the head is scarcely wider than the neck. Head width (widest point) $7.3 \mathrm{~mm}$, head length (snout tip to rear edge of quadrate) 8.9 $\mathrm{mm}$, the latter representing $3.0 \%$ of snout-vent length. Rostral undivided, as broad as deep, and separating the nasals. Internasals narrowly in contact behind the rostral, while there is a large azygous scale, almost as large as a prefrontal, separating the prefrontals. Frontal 2.25 times longer than broad, while each supraocular is about the same width as the frontal. Seven supralabials on each side, the second and third contacting the eye. Nine infralabials on each side, the count being confused by a series of splintlike marginal scales separating the anterior infralabials from the lip margins. Temporals $1+3$ on each side. Postmental scale (sensu McCarthy, 1986) absent.

Number of scale rows around the body (excluding the ventrals) at the 20th, 50th, 100th, 150th and 200th ventrals 


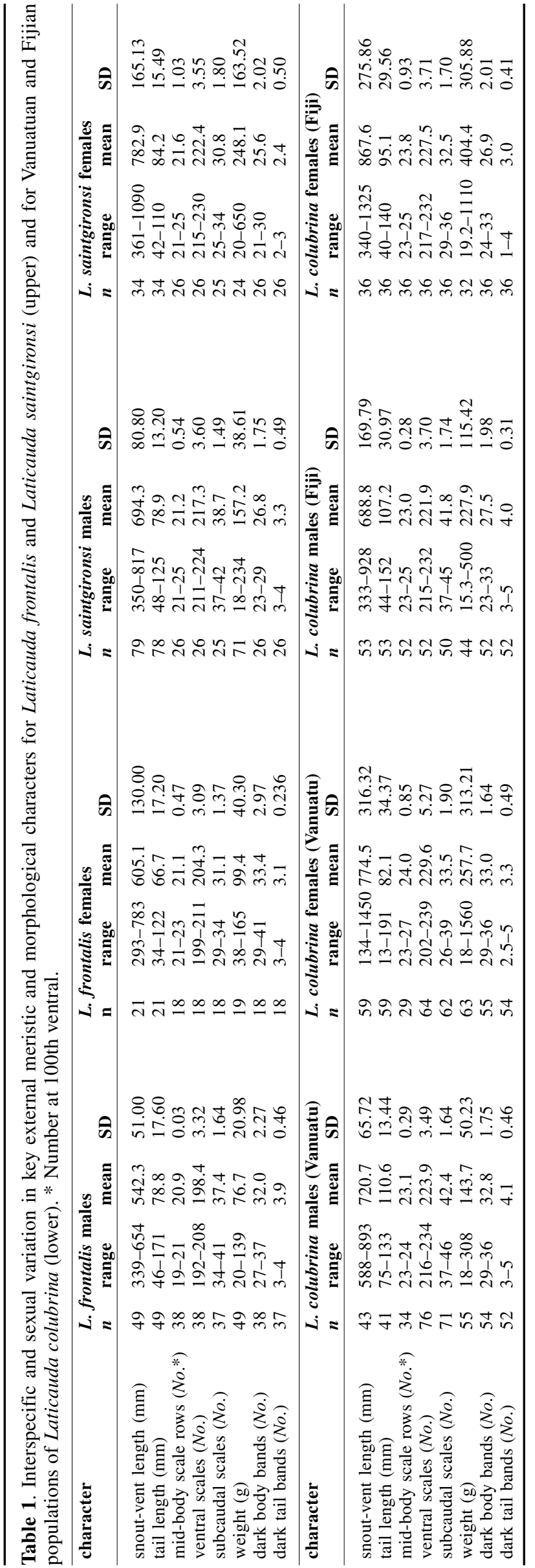

respectively are $21,21,21,21$, and 19 . There are 203 ventral scales (gastrosteges) and 31 divided subcaudal scales, indicating that it is a female (specimen not dissected). The snout-vent length is c. $293 \mathrm{~mm}$ (several counts; the specimen is badly kinked in preservation) while the tail length is $34 \mathrm{~mm}$.

Thirty-one dark body bands and 3 dark caudal bands; the first body band is not connected laterally to the nuchal band (see Fig. 2, upper). This is the smallest specimen of this species seen by the authors, and possesses the characteristic juvenile condition of ventrally incomplete dark cross-bands, the latter generally extending only to the middle or lower parts of the flanks.

Variation. Variation in a number of phenotypic character states in Laticauda frontalis is compared in Table 1 with variation in the same characters for syntopic Laticauda colubrina (from Vanuatu), for Laticauda colubrina from the Fiji Islands to the east, and from Laticauda saintgironsi from New Caledonia to the south.

The extent to which the dark bands fail to meet ventrally varies ontogenetically. All dark bands are usually incomplete in juveniles and subadults, while in large adults usually only those bands on the anterior part of the body may remain incomplete.

The centre of the heart is located between ventrals 67 and $75($ mean $=70.6, \mathrm{SD}=2.37, n=10)$.

Distribution. The holotype of Laticauda frontalis is said to have come from "New Guinea"; if this provenance is correct then it is the only specimen currently known outside the region encompassing Vanuatu and the Loyalty Islands. P. Couper (in litt.) of the Queensland Museum advises that there is no additional documentation associated with the holotype's original acquisition that might provide more accurate information about its provenance (including any doubt or uncertainty) or the unknown donor/collector. All of our fieldacquired specimens were collected on two island complexesEfate and Espiritu Santo-in the Republic of Vanuatu (formerly the British-French condominion of the New Hebrides).

There is a single specimen in the Macleay Museum, University of Sydney (MM 633) and another in the Muséum national d'Histoire naturelle, Paris (HFH) from the Loyalty Islands (the easternmost islands of New Caledonia located about one-third of the distance between New Caledonia's main island (Grande Terre) and the southernmost islands of Vanuatu). The species has not been recorded from the Solomon Islands to the northwest of Vanuatu, nor from New Caledonia's main island complex. Consequently we regard the current distribution of the species to be confined to the Loyalty Islands and the islands of Vanuatu, at least as far north as the island of Espiritu Santo. And in the absence of any records of this species from New Guinea since it was described in 1905, and without secondary sources to confirm the original type locality, we regard either the type locality of "New Guinea" to be erroneous or the holotype to be a waif individual originating from the Vanuatu region. In all of the features used above to characterize this species, the holotype falls within the range of variation recorded in specimens from Vanuatu.

Ecology. Like other members of the Laticauda colubrina species complex, Laticauda frontalis feeds exclusively on eels belonging to several families-most commonly those in the families Muraenidae and Congridae (Reed et al., 2002). 


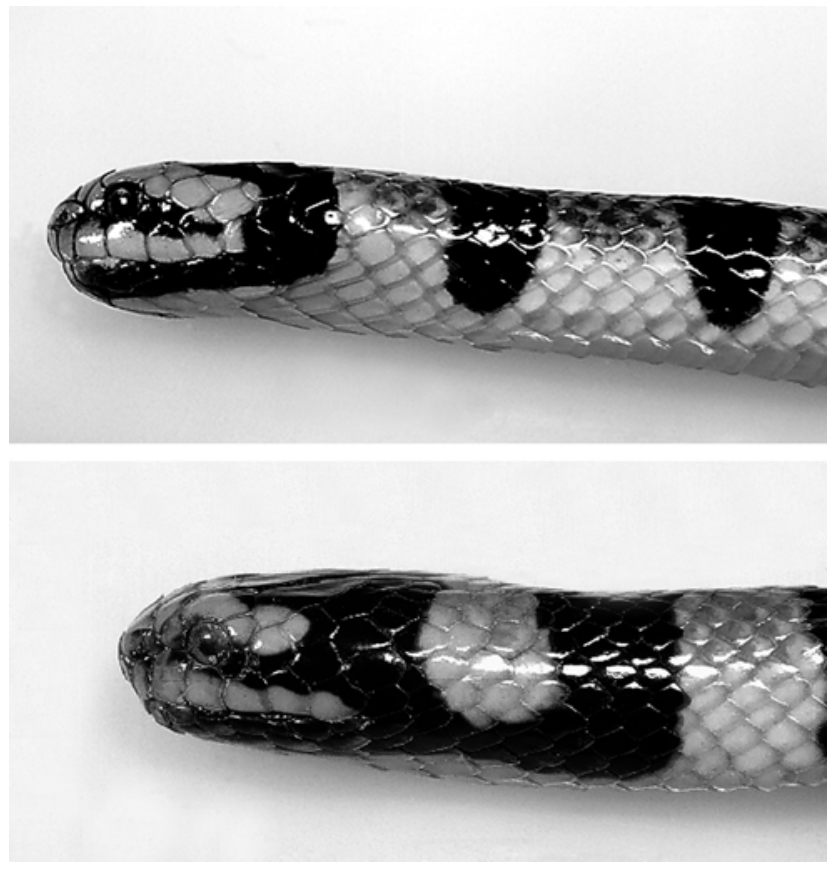

Fig. 2. Lateral head pattern diagnostic of sympatric populations of Laticauda frontalis (upper) and Laticauda colubrina (lower) in Vanuatu. Note that the nuchal band is never linked, laterally, to the first body band in $L$. frontalis and very rarely unlinked in Vanuatuan L. colubrina.

This species was long confused with juveniles and subadults of the sympatric and syntopic Laticauda colubrina, not only because of their morphological similarity but in large part because the two species could be found together, both in terrestrial aggregations and in aquatic feeding sites. On some small coral islets within the lagoon at Panangisu on the northern side of Efate Island in Vanuatu, individuals of both species were found coiled up together under the same rock or pile of decaying vegetation, or in wave-eroded cavities and crevices in the exposed perimeter calcarenitic rock above high tide level but well within the splash zone.

Other individuals were found in cavities in the wide, flat calcarinite platforms that make up the supralittoral zone around many parts of the larger islands, even close to major urban centres such as the national capital of Port Vila, on Efate Island. At night the snakes could be found emerging from the sea onto these platforms, or moving across them $100 \mathrm{~m}$ or more from the sea.

Maximum prey size is broadly correlated with body size in anguillophagous sea kraits, and so the dwarf frontalis competes for prey with similar-sized (generally sub-adult) members of the larger syntopic Laticauda colubrina (Shine et al., 2002b).

Material examined. Numerous live specimens captured for venom extraction were examined for a variety of mensurable and meristic characters before being released back into the wild. Heatwole et al. (2005) list additional specimens examined by only one of us (HFH) in other museum collections, but the following specimens assigned by us to this species were preserved and lodged in the herpetological collections of the Australian Museum, Sydney: R164858-68 ð̊ ठ, R164869-

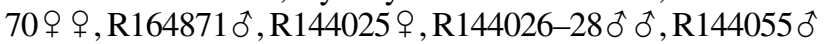
from Pango Point at Pango (Etang) Village, near Port Vila,
Efate Island, Vanuatu; R164872-79 đ̊ ô, R144020 ㅇ, R144021-22 $\hat{0} \widehat{\widehat{o}}$ from Niogoriki Island, off Paunangisu Village, N. coast of Efate Island, Vanuatu; R164880-81 ôे ô, from W. side of Mele Bay, Port Vila, Efate Island, Vanuatu;

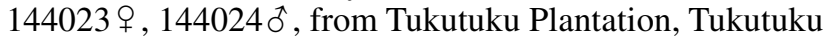
Bay, Efate Island, Vanuatu.

\section{Laticauda saintgironsi n.sp.}

Holotype. Australian Museum, Sydney (AMS) R162999 (AMS field no. 34602), an adult male from Porc-épic Island, Le Lagon, near Noumea, New Caledonia collected by the authors on 14 September 1993, 22 $2^{\circ} 9^{\prime} 45.6^{\prime \prime S ~ 166 ~ 34 ' 08.5 " E . ~}$

Paratypes. All paratypes are from localities within New Caledonia and are lodged in the Australian Museum, Sydney (AMS): R78031 0 , R78032 9 , R78035-38웅, R78042우, R78043ㅇ, R78046우 from Île Mouac;

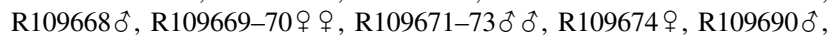
$\mathrm{R} 109691$ ㅇ, R109692 $\hat{0}, \mathrm{R} 109693$ 우, R109694-98 ô ô, R109699우 from Île Redika; R109681 ㅇ, R109682-83 ô ô, R109684 ㅇ, R109685 ठै, R109686 + , R109687 ô, R109688 i, R109689 의 from Île Grand Mato;

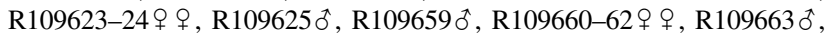

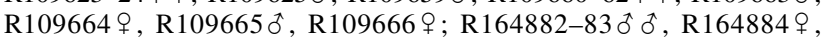

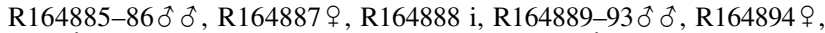
from Île Porc épic, near Noumea; R78086 đ̊ from Île Noue; R144070-

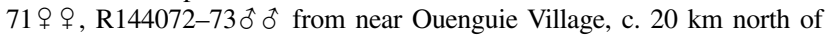
Hienghene; R144065 $\delta$ from south of Mou, east coast; R144069 $\hat{\jmath}$ from c. $5 \mathrm{~km}$ SE of Koulnoue Village, near Hienghene; R144094-96 $\hat{0} \hat{~}$ from near Malabou Beach Hotel, Baie de la Nehoue, c. $5 \mathrm{~km} \mathrm{~S}$ of Poum. The letter i refers to immature/indeterminate specimens.

Other specimens examined included living individuals that were weighed, measured and scalation examined before being released back into the wild; other specimens examined by one of the authors (HFH) are listed and discussed in Heatwole et al. (2005).

Diagnosis. A banded sea krait of the genus Laticauda characterized by the possession of a yellow or cream upper lip, an undivided rostral scale, usually 21 mid-body scale rows in both sexes (but occasionally 23 or rarely 25 rows, mode 21 in both sexes), ventral scales from 211 to 224 in males and from 215 to 230 in females, and a maximum snoutvent length (SVL) of $817 \mathrm{~mm}$ (males) and $1090 \mathrm{~mm}$ (females). It can be distinguished from L. laticaudata and $L$. crockeri by its yellow upper lip (black or dark brown in laticaudata and crockeri) and from $L$. semifasciata and $L$. schistorhyncha by its pale upper lip and undivided rostral (upper lip brown and rostral divided in semifasciata and schistorhyncha).

From the nearest populations (Fiji and Vanuatu) of its allopatric congener $L$. colubrina it may be distinguished by a lower modal mid-body scale row count of 21 , its lower ventral scale counts (Table 1, Fig. 8); smaller size (Table 1); dark body bands either not meeting ventrally or narrowing ventrally, often with a pale mid-ventral blotch; and its distinctive body colour in which the paler bands are predominently brown (fawn to rich russet $v s$ steely grey or blue in L. colubrina).

From $L$. frontalis is may be distinguished by its larger size and higher ventral and subcaudal counts (Table 1) and the distinctive brown dorsal colour (grey or blue-grey in frontalis).

Description of the holotype. A typical member of the Laticauda colubrina complex in shape, with a relatively slender body in which the mid-body diameter is contained 33.3 times in its snout-vent length and the head is scarcely 
wider than the neck. Head width (widest point) $16.2 \mathrm{~mm}$, head length (snout tip to rear edge of quadrate) $21.8 \mathrm{~mm}$, the latter representing $3.0 \%$ of snout-vent length. The rostral is undivided, about as broad as deep, and separates the nasals, each of which contacts the single preocular scale on each side. The internasals are about as large as the prefrontals, meeting broadly in the middle. The prefrontals are separated posteriorly by a large azygous scale, about equal in size to one of the internasals. A single, large supraocular scale on either side of the frontal. The latter is only slightly longer than broad. Six supralabials on each side, the third and fourth entering the eye. One anterior temporal scale on each side, and two posterior temporals. Six or seven infralabials, though the counts are uncertain because all but the first three infralabials are excluded from the lip by an irregular series of splint-like marginal scales.

There are 21 mid-body scale rows. Body scale row numbers are reduced only posteriorly, with 21 rows at the 20th, 50th, 100th and 150th ventrals and 19 rows at the 200th ventral. There are 218 ventral scales and 38 pairs of subcaudal scales. The snout-vent length (SVL) in life was $727 \mathrm{~mm}$, while the tail length was $88 \mathrm{~mm}$. The live weight was $185 \mathrm{~g}$.

The colour pattern (Figs. 2 and 3) consists of a broad black band across the back of the head, extending forward to about the middle of the frontal scale; this band is joined laterally on each side by a broad dark stripe from behind the eye and another continuous black stripe below each lower jaw. At the point where these all meet there is a broad lateral black bar linking the dark head band to the first neck band. There are 28 black bands on the trunk and four on the tail. All of these black bands extend right around the body, but most trunk bands also have a pale, mid-ventral blotch. Along the vertebral line the pale bands between the black bands are $60-66 \%$ as wide as the black bands.

In life, the colour of the holotype from above was bright russet-orange, fading gradually on the flanks to a pale cream or white, but with many of the individual scales tipped or edged with black or dark blue-grey, giving the pale bands a reticulated appearance; the dark bands were glossy black. Ventrally the colour was creamy-white, with the margins of the ventral scales slightly darker-edged with pale brown. Most of the scales on the head and lips are finely margined with black, emphasizing the sutures.

Variation. The general appearance and non-diagnostic scalation varies little from that described for the holotype above. As in all Laticauda there is marked sexual dimorphism in body mass and relative tail length, sometimes exaggerated in older (larger) individuals Variation in those principal morphological characters used in diagnosing the species are given in Table 1 and Figs. 4-7. In both cases the variables for Laticauda saintgironsi are compared with those in adjacent regional populations of both Laticauda colubrina and Laticauda frontalis.

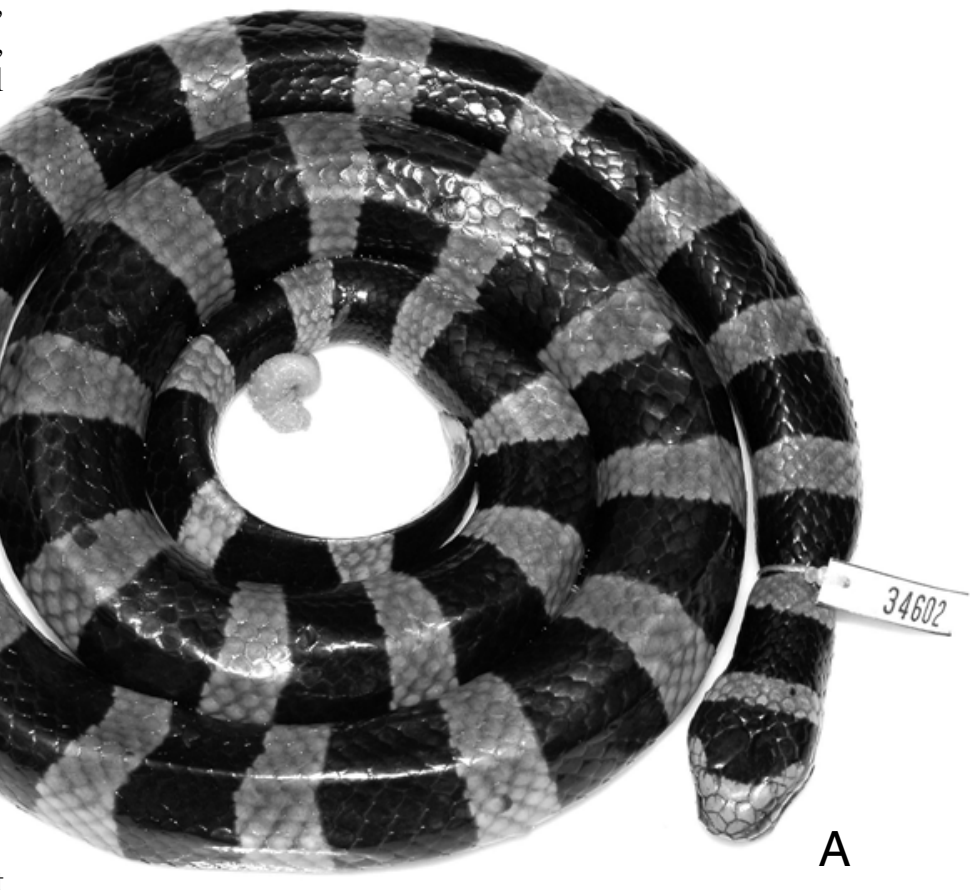

A

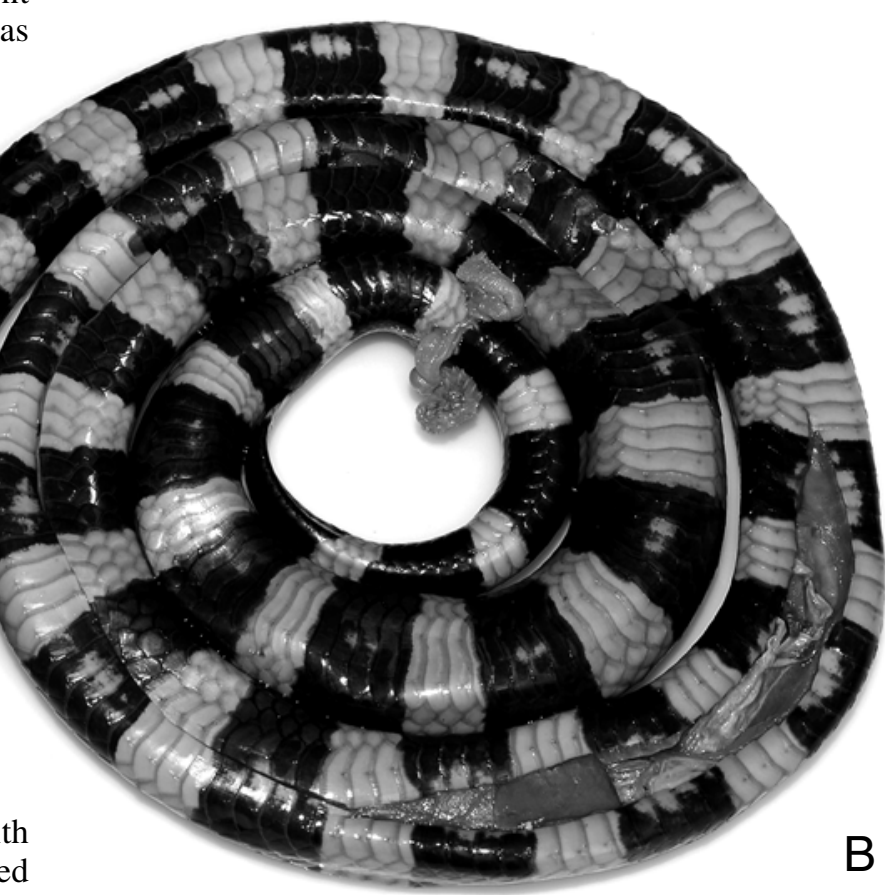

Fig. 3. (A) Dorsal view of holotype, AM R162999, of Laticauda saintgironsi from Porc-épic Island, Le Lagon, near Noumea, New Caledonia. (B) Ventral view of holotype, AM R162999, of Laticauda saintgironsi from Porc-épic Island, Le Lagon, near Noumea, New Caledonia.

The number of scale rows around the body (excluding the ventrals) varies along the length of the body, as shown in Table 1 for (usually) five points along the body-at the 20th, 50th, 100th, 150th and either the last or 200th ventral (whichever came first), but the mid-body count is mostly 21 in males and females (Fig. 9) and only occasionally 23 or 25. The ventral scales range from 211-230 (Table 1, Fig. 8 ) and the paired subcaudal scales range from 25-42 (37- 

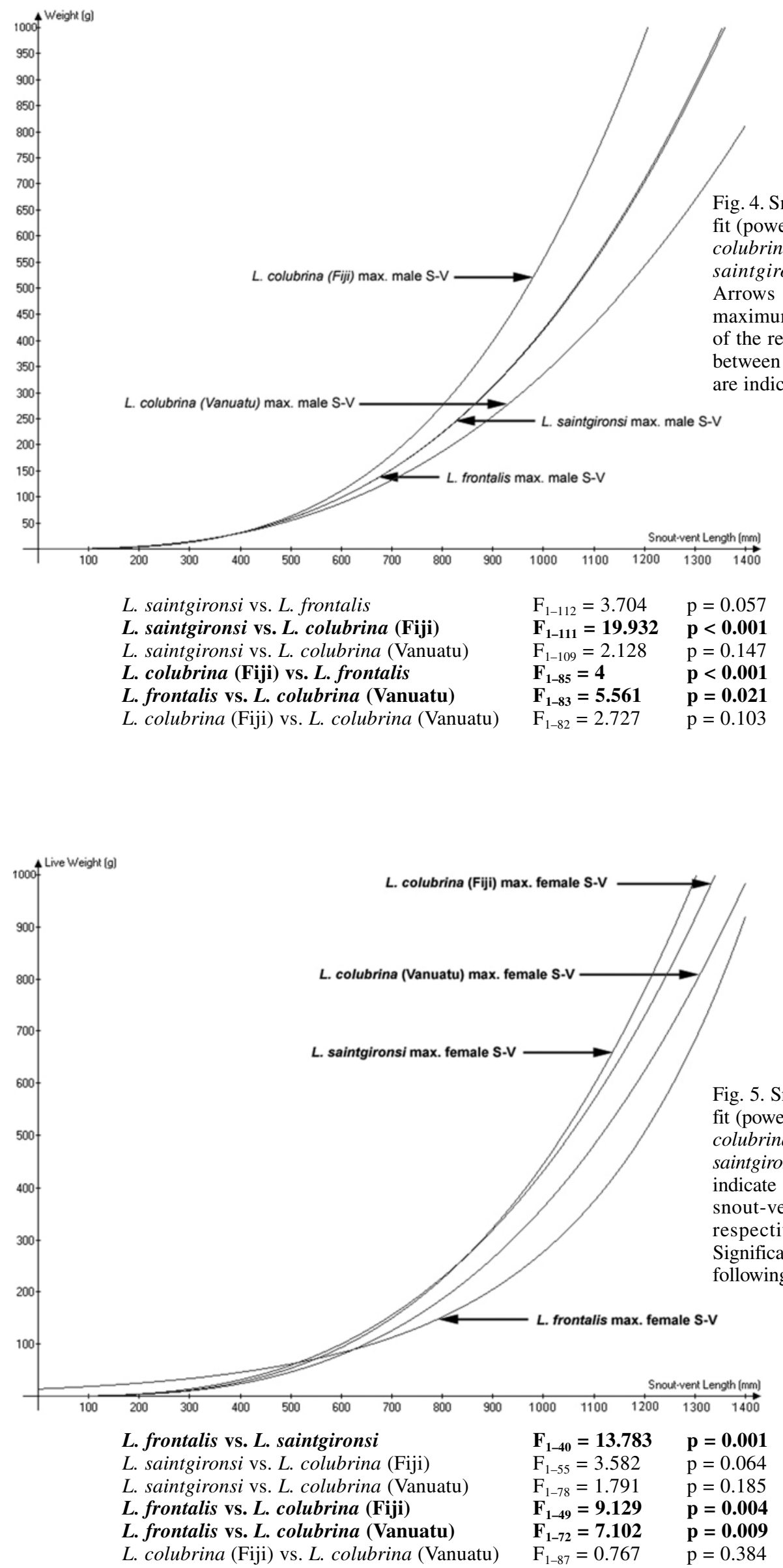

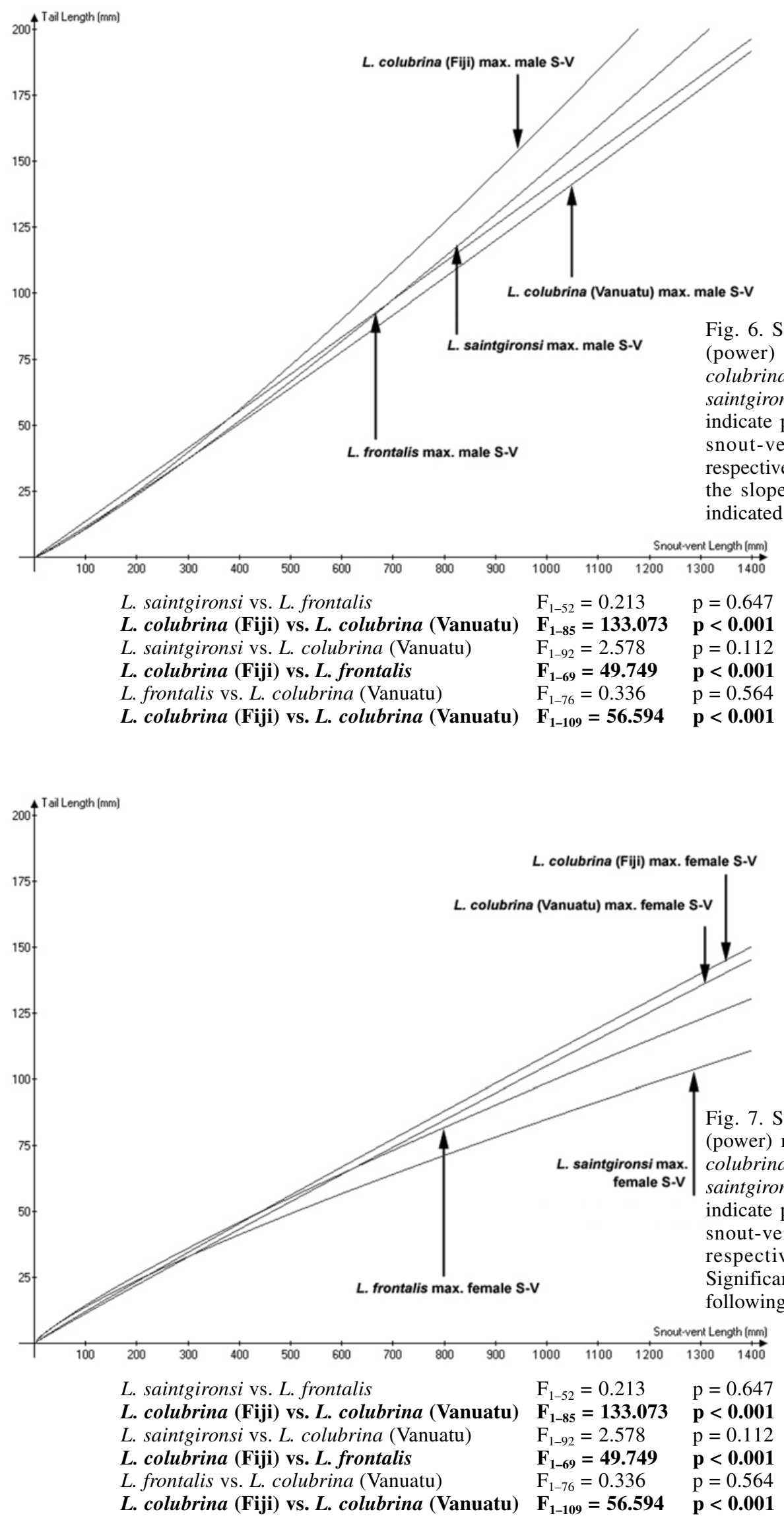


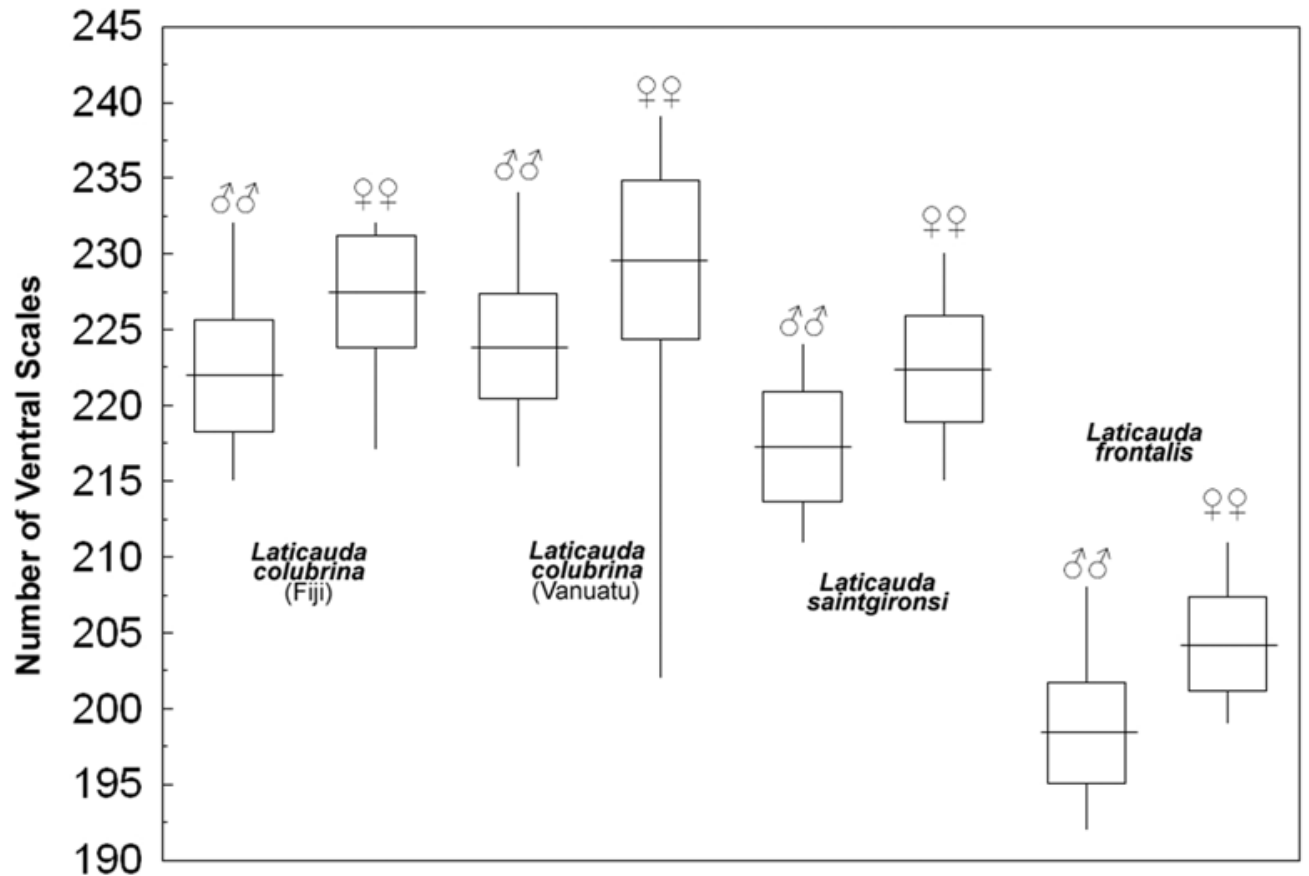

Fig. 8. Geographic and sexual variation in ventral scale numbers in Laticauda frontalis, Laticauda saintgironsi and two regional populations of Laticauda colubrina. Vertical line indicates range; horizontal line represents mean; rectangle represents 2 standard deviations.

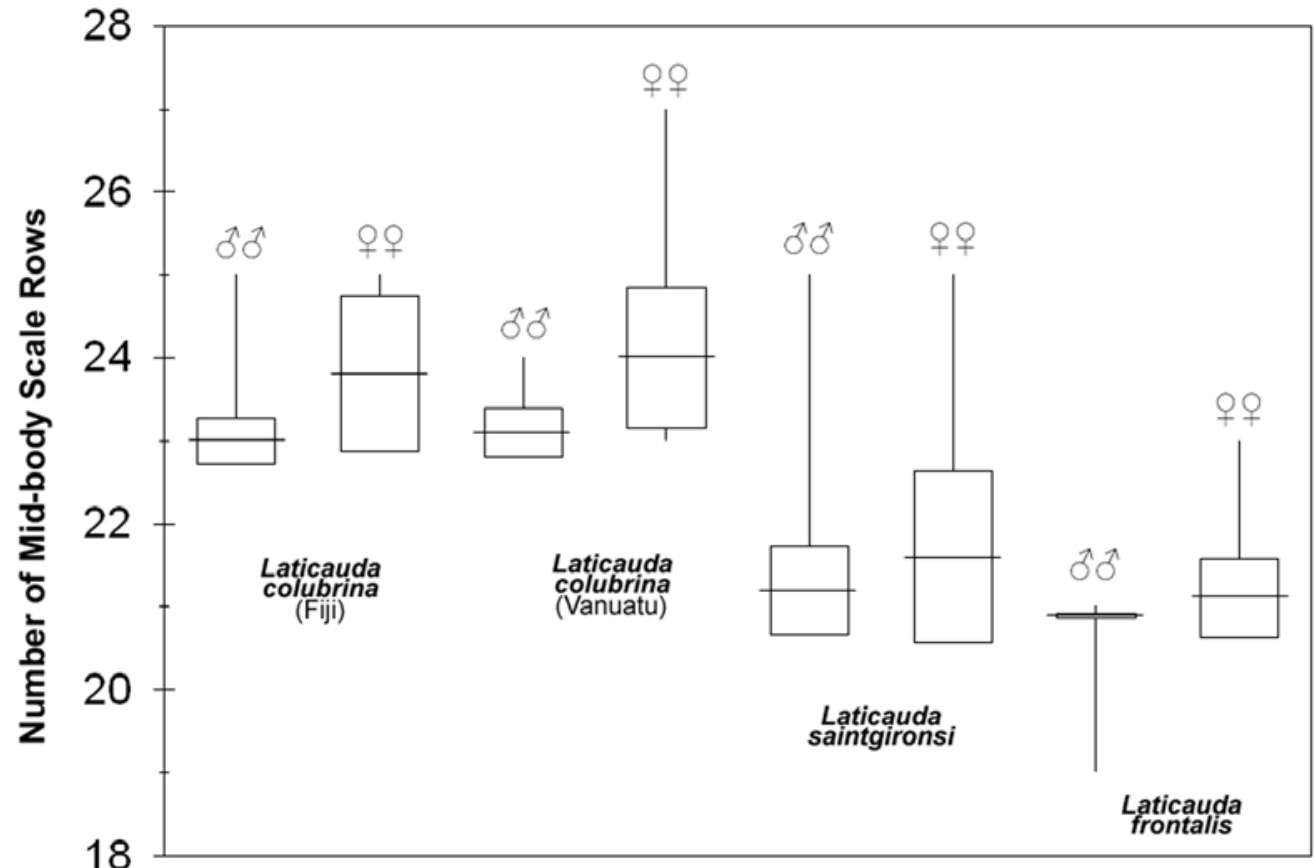

Fig. 9. Geographic and sexual variation in mid-body scale row numbers in Laticauda frontalis, Laticauda saintgironsi and two regional populations of Laticauda colubrina. Vertical line indicates range; horizontal line represents mean; rectangle represents 2 standard deviations. 


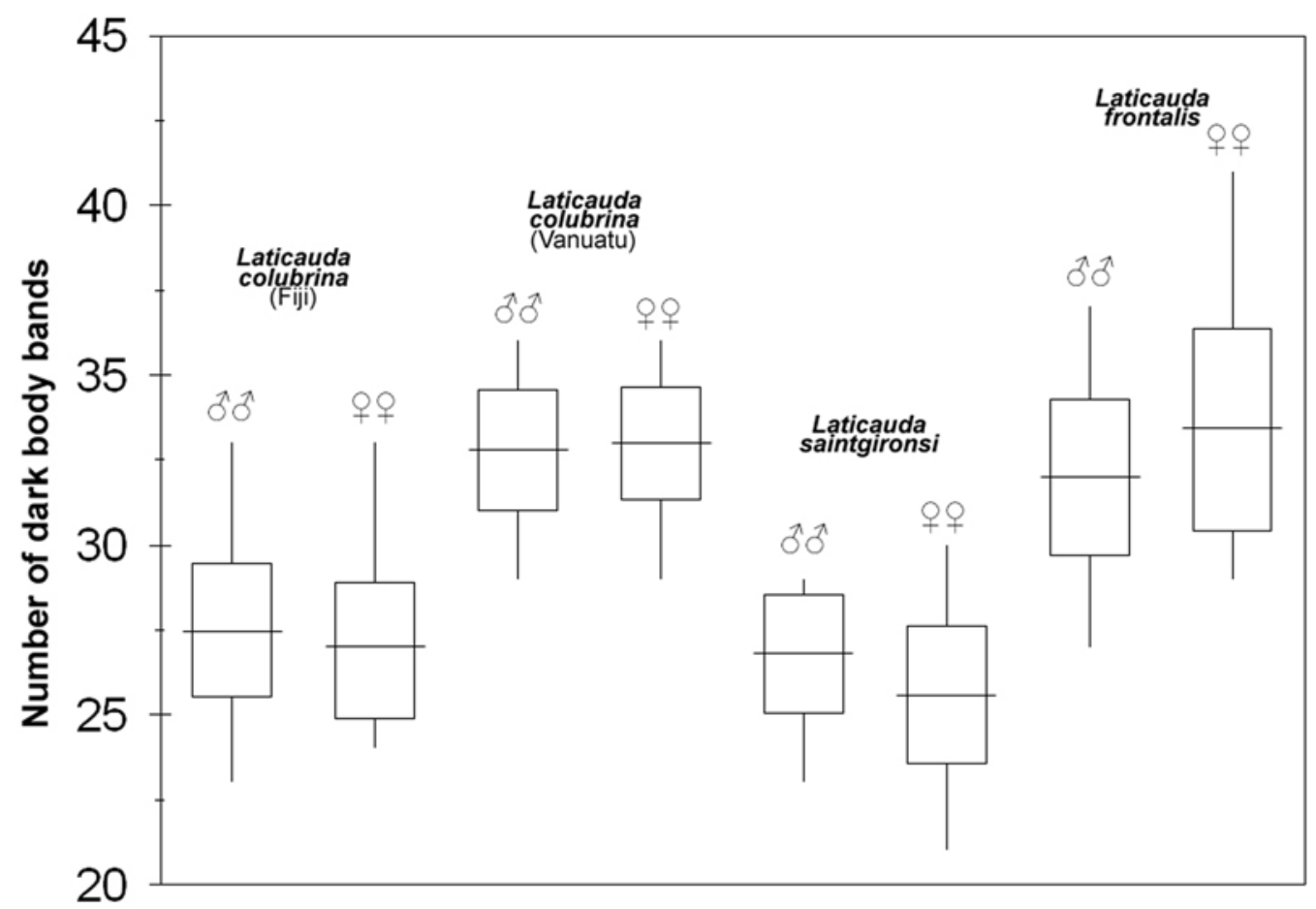

Fig. 10. Geographic and sexual variation in numbers of dark body bands in Laticauda frontalis, Laticauda saintgironsi and two regional populations of Laticauda colubrina. Vertical line indicates range; horizontal line represents mean; rectangle represents 2 standard deviations.

42 in males, 25-34 in females, Table 1). The total number of dark body bands ranges from 23-29 (males) and 21-30 (females), while the number of dark tail bands ranges from 3-4 (males) and 2-3 (females).

Distribution. Known only from the French Territory of New Caledonia, where it occurs around the entire coast of the main island (Grande Terre) and its many offshore islands, often in very large numbers locally. It is recorded from the Loyalty Islands, but there are no current records there of syntopy with its closest congener, Laticauda frontalis.

Ecology. This is a typical member of the Laticauda colubrina complex, spending much of its time in coastal waters feeding on a variety of eels in shallow reef waters, alternating with periods spent ashore sheltering in shoreline vegetation, piles of dense litter, or, on rocky shorelines, in crevices and caves, or under boulders. They may travel some hundreds of metres inland, and climb to the tops of rocky hills and islands that may be $100 \mathrm{~m}$ or more in elevation. Aggregations of 30 or more individuals are often encountered in single refuges, while some hundreds of individuals may be found on individual small islands within the lagoons of large reef systems.

An extensive summary of the distribution and ecology of this species, under the name Laticauda colubrina, has recently been provided by Ineich \& LaBoute (2002). Other studies, also as L. colubrina, include St Girons (1964), McCarthy (1986) and Shine et al. (2003). The species is abundant and wide-ranging around the coast of New Caledonia and its numerous off-shore islands.
Etymology. This species in named for the late Dr Hubert Saint Girons, whose many outstanding contributions to international herpetology ranged across disciplines and continents. In order for future workers to clearly identify the patronym, the name saintgironsi is formed directly from the modern personal name as a noun in the genitive case.

\section{Discussion}

The discovery that Laticauda frontalis is a dwarf species living sympatrically and syntopically with Laticauda colubrina in Vanuatu, the two morphologically almost indistinguishable and exploiting and competing for the same aquatic and terrestrial microhabitats and food resources, raises two obvious questions: how do these species maintain their ecological integrity without one displacing the other? and how did this situation evolve in the first place?

Published morphological and molecular genetic data (e.g., McCarthy, 1986) indicate that living laticaudine species, especially Laticauda colubrina s.l., display significant regional variation but with a level of overlap that makes recognition of separate taxa difficult and ambiguous. Until further molecular data are available that might help to answer these questions, only tentative explanations can be offered.

The available data suggest that $L$. frontalis and $L$. saintgironsi are sister species representing a distinct lineage within the colubrina complex, bringing the total number of recognized species in this complex to four (with colubrina and guineai). The former species-pair share a small suite of 
characters in common, though these characters are largely expressed through modal values: low variability in body scale rows numbers, lower ventral scale counts, lower subcaudal counts, and lower body band numbers (Table 1, Figs. 8-10). These differences are also reflected in other measures of body form. Laticauda saintgironsi and $L$. frontalis share similar regression curves, by sex, for snoutvent length $v s$. tail length (Figs. 6-7) and snout-vent length vs live weight (Figs. 4-5) when compared with curves for sympatric or adjacent populations of $L$. colubrina.

Research on the venom chemistry of these two species indicate only minor differences in amino acid residues in laticotoxin sequences, shared by $L$. frontalis and $L$. saintgironsi, that separate both from syntopic or geographically proximate populations of $L$. colubrina from Vanuatu and Fiji (T. Tamiya, N. Tamiya, pers. comms.).

The current distribution of Laticauda within the southwest Pacific region appears to be the outcome of a series of speciation events involving local or regional isolation of populations of widespread taxa, followed in turn by reinvasions of the widespread parent species that, through subsequent morphological and ecological character displacement, resulted in either sympatry or mutual exclusion of closely allied congeners.

If, as we propose, the dwarf Laticauda frontalis represents a paedomorphic member of the L colubrina complex, then it must clearly be derived from one of the larger members of the complex. Given its many shared features with the larger, non-paedomorphic $L$. saintgironsi, and their marginally overlapping geographic ranges, one likely explanation is that frontalis evolved in the southern part of Vanuatu where saintgironsi (or its endemic New Caledonian precursor) came into contact with the northern colubrina. Their common ecologies may well have put considerable pressure on either species to minimize ecological competition by selecting for early maturity, and its associated reduction in body size, by utilising an inherent predisposition to progenesis in this group of snakes. Current work in preparation suggests that both Laticauda crockeri and Laticauda schistorhynchus also represent localized paedomorphic species derived from once geographicallyisolated outliers of more widespread Laticauda species. Progenesis offers a built-in mechanism for rapid speciation, consistent with the available evidence that genetic variability in members of the L. colubrina complex is low and that existing differences are of relatively recent origin. We hypothesize that Laticauda frontalis and Laticauda saintgironsi represent a distinct lineage (clade) within the Laticauda colubrina complex.
ACKNOWLEDGMENTS. The authors are especially grateful to Professors Nobuo Tamiya (then of Tohoku University, Sendai, Japan) and Professor Toru Tamiya (Sophia University, Tokyo, Japan) for including us in their programs of research into the venom chemistry of laticaudine sea kraits between 1982 and 1996 and who, with Dr Ken Zimmerman, contributed to the collection of specimens in the field. Mr Patrick Couper kindly made available the type of Laticauda frontalis in the Queensland Museum. Drs Richard Major and Alan Jones provided valued advice and assistance in statistical procedures and interpretation. We are also very grateful to Elizabeth Cameron for her assistance over many years in building an extensive database on large numbers of marine snakes acquired in the course of numerous field trips in Asia and the South Pacific.

\section{References}

Alvarez del Toro, M., 1982. Los reptiles de Chiapas (3a ed., corr. y aum). Tuxtla Gutiérrez, Chiapas, México: Instituto de Historia Natural [not seen; cited from secondary source].

Cadle, J.E., \& G.C. Gorman, 1981. Albumin immunological evidence and the relationships of sea snakes. Journal of Herpetology 15(3): 329-334.

Cogger, H.G., 1975. The Sea Snakes of Australia and New Guinea. In The Biology of Sea Snakes, ed. W. Dunson, pp. 59-139. Baltimore: University Park Press.

Cogger, H.G., H. Heatwole, Y. Ishikawa, M. McCoy, N. Tamiya \& T. Teruuchi, 1987. The status and natural history of the Rennell Island sea krait, Laticauda crockeri (Serpentes: Laticaudidae). Journal of Herpetology 21(4): 255-266.

de Vis, C.W., 1905. A new genus of lizards. Annals of the Queensland Museum 6: 48

Enderman, H., 1970. A classification of the sea snakes with notes on geographic variation. Leiden: Rijksmuseum van Natuurlijke Historie. [Unpublished manuscript].

Golay, P., H.M. Smith, D.G. Broadley, J.R. Dixon, C. McCarthy, J.C. Rage, B. Schätti \& M. Toriba, 1993. Endoglyphs and Other Major Venomous Snakes of the World: A Checklist. Azemiops S.A., Herpetological Data Centre, Geneva. xv +478 pp.

Gorman, G.C., 1981. The chromosomes of Laticauda and a review of karyotypic evolution in the Elapidae. Journal of Herpetology 15(2): 225-233

Greer, A.E., 1998 [1997]. The Biology and Evolution of Australian Snakes. Sydney: Surrey Beatty \& Sons, pp. xii +350 .

Guinea, M.L., 1986. Aspects of the Biology of the Common Fijian Sea Snake Laticauda colubrina (Schneider). Unpublished MSc thesis, University of the South Pacific, Suva, Fiji.

Heatwole, H., S. Busack \& H. Cogger, 2005. Geographic variation in sea kraits of the Laticauda colubrina complex (Serpentes: Elapidae: Hydrophiinae: Laticaudini). Herpetological Monographs 19: 1-136.

Ineich, I., \& P. LaBoute, 2002. Les serpents marins de NouvelleCalédonie/Sea snakes of New Caledonia. IRD éditions, Institut de Recherche pour le Dévelopment, Muséum national d'histoire naturelle, Paris, pp. 1-302. [French and English dual texts].

Keogh, J.S., R. Shine \& S.C. Donnellan, 1998. Phylogenetic relationships of terrestrial Australo-papuan elapid snakes (subfamily Hydrophiinae) based on Cytochrome b and 16S rRNA sequences. Molecular Phylogenetics and Evolution 10: 67-81.

Kharin, V.E., 1984. Revision of sea snakes of subfamily Laticaudinae Cope, 1879 sensu lato (Serpentes, Hydrophiidae). [Title translated from the original Russian]. Transactions of the Zoological Institute of the USSR Academy of Sciences 124: $128-139$.

Lord, C.E., 1919. Notes on the snakes of Tasmania. Papers \& Proceedings of the Royal Society of Tasmania 1918: 76-81. 
McCann, C., 1966. The marine turtles and snakes occurring in New Zealand. Records of the Dominion Museum 5(21): 201-215.

McCarthy, C.J., 1986. Relationships of the laticaudine sea snakes (Serpentes: Elapidae: Laticaudinae). Bulletin of the British Museum of Natural History (Zoology) 50(2): 127-161.

McDowell, S.B., 1985. The terrestrial Australian elapids: general summary. In The Biology of Australasian Frogs and Reptiles, ed. G.C. Grigg, R. Shine and H.F.W. Ehmann, pp. 261-264. Sydney: Surrey Beatty and Sons with Royal Zoological Society of New South Wales.

McDowell, S.B., 1987. Systematics. In Snakes: Ecology and Evolutionary Biology, ed. R.A. Seigel, J.T.C. Collins and S.S. Novak, pp. 1-50. New York: Macmillan.

Reed, R.N., R. Shine \& S. Shetty, 2002. Sea kraits (Squamata: Laticauda spp) as a useful bioassay for assessing local diversity of eels (Muraenidae, Congridae) in the western Pacific Ocean. Copeia 2002(4): 1098-1101.

Saint Girons, H., 1964. Notes sur l'ecologie et la structure des populations des Laticaudinae (Serpents, Hydrophidae) en Nouvelle Caledonie. La Terre et la Vie 2-1964: 185-214.

Scanlon, J.D., \& M.S.Y. Lee, 2004. Phylogeny of Australasian venomous snakes (Colubroidea, Elapidae, Hydrophiinae) based on phenotypic and molecular evidence. Zoologica Scripta 33(4): 335-363.

Shetty, S., 2000. Behavioural ecology of the yellow-lipped sea krait, Laticauda colubrina, in the Fiji Islands. Unpublished thesis, School of Biological Sciences, University of Sydney.

Shine, R., H.G. Cogger, R.N. Reed, S. Shetty \& X. Bonnet, 2003. Aquatic and terrestrial locomotor speeds of amphibious seasnakes (Serpentes, Laticaudidae). Journal of Zoology (London) 259: 261-268.

http://www.bio.usyd.edu.au/Shinelab/shine/reprints/371aquaticterrestrial.pdf
Shine, R., R.N. Reed, S. Shetty \& H.G. Cogger, 2002a. Relationships between sexual dimorphism and niche partitioning within a clade of sea-snakes (Laticaudinae). Oecologia 133: 45-53.

Shine, R., R.N. Reed, S. Shetty, M. LeMaster \& R.T. Mason, 2002b. Reproductive isolating mechanisms between two sympatric sibling species of sea-snakes. Evolution 56: 16551662.

http://www.bio.usyd.edu.au/Shinelab/shine/reprints/352reproductiveisolating.pdf

Slowinski, J.B., \& J.S. Keogh, 2000. Phylogenetic relationships of elapid snakes based on cytochrome b mtDNA sequences. Molecular Phylogenetics and Evolution 15(1): 157-164.

Smith, M.A., 1926. Monograph on the Sea Snakes. (Hydrophiidae). London: British Museum, xvii+130 pp.

Tamiya, N., 1985. A comparison of amino acid sequences of neurotoxins and of phospholipases of some Australian elapid snakes with those of other proteroglyphous snakes. In The Biology of Australasian Frogs and Reptiles, ed. G.C. Grigg, R. Shine and H.F.W. Ehmann, pp. 209-219. Sydney: Surrey Beatty and Sons with Royal Zoological Society of New South Wales.

Tamiya, N., A. Sato, H.S. Kim, T. Teruuchi, C. Takasaki, Y. Ishikawa, M.L. Guinea, M. McCoy, H. Heatwole \& H.G. Cogger, 1983. Neurotoxins of sea snakes genus Laticauda. Toxicon Supplement 3: 445-447.

Villa, J., 1962. Las serpientes venenosus de Nicaragua. Managua. [Not seen; cited from secondary source].

Manuscript received 26 July 2005, revised 13 February 2006 and accepted 22 February 2006.

Associate Editor: Sandy Ingleby. 